\title{
Risk Factors Associated with Higher Injection Drug Use and HIV Rates: Findings from Saskatchewan, Canada
}

\author{
John Moraros ${ }^{1 *}$, Jacey Falconer ${ }^{2}$, Marla Rogers ${ }^{3}$ and Mark Lemstra ${ }^{4}$ \\ ${ }^{1}$ Assistant Professor, School of Public Health, University of Saskatchewan, Canada \\ ${ }^{2}$ Student, School of Public Health, University of Saskatchewan, Canada \\ ${ }^{3}$ Researcher, School of Public Health, University of Saskatchewan, Canada \\ ${ }^{4}$ Adjunct Professor, School of Public Health, University of Saskatchewan, Canada
}

\section{Abstract}

Background: Over the last decade, the incidence of positive HIV test reports within the Saskatoon Health Region (SHR), Saskatchewan, and Canada has been rapidly rising. Injection drug use (IDU) has been widely recognized as the major etiological factor for this increase. This study sought to assess the prevalence, characteristics, and risk indicators of higher risk injection drug use (HR IDUs) in comparison to lower risk injection drug use (LR IDUs) within the SHR, Saskatchewan, and Canada.

Methods: This is a cross sectional study. Study participants were selected over an eight month period spanning from 2009 to 2010. During that time period current IDUs $(n=603)$ were interviewed and stratified into either the HR IDUs $(n=182)$ or LR IDUs $(n=421)$ categories depending on their drug use behaviours and needle and paraphernalia sharing practices.

Results: This study found that HR IDUs were more often engaged in giving sex to get drugs and giving drugs to get sex than LR IDUs. HR IDUs also had significantly more sexual partners and a higher frequency of injection than LR IDUs. Logistic regression analysis, determined three covariates that independently predicted being a HR IDU including homelessness, having experienced sexual assault as a child, and lack of knowledge related to HIVIAIDS.

Conclusions: The findings of the present study provide valuable information to health care professionals and a useful context based on which public health initiatives can be designed to specifically target IDUs, who are most at risk in developing HIV and subsequently transmitting the disease.

Keywords: Injection drug use; Risk factors; HIV/AIDS; Aboriginal populations; Canada

\section{Introduction}

Over the last decade, there has been a rapid and disconcerting rise in the number of HIV positive test reports in the Saskatoon Health Region (SHR), Saskatchewan, and Canada. There were 16 HIV positive test reports confirmed in 2004, followed by 39 in 2005, 53 in 2006, 57 in 2007, 77 in 2008, and 94 in 2009. The annual incidence of positive HIV test reports in 2008 in the SHR was more than three times the national average in Canada (31.3 and 9.3 per 100,000 population respectively) [1]. In 2008, 76.9\% (133 of 173) of the positive HIV test reports in Saskatchewan were associated with injection drug use (IDU) [2]. In comparison, Canada had only $18.9 \%$ of the positive adult HIV test reports attributed to IDU in 2008 [3].

Recent studies in Vancouver and Saskatoon, Canada also found that the mode of transmission of HIV has changed considerably. In the past, HIV was primarily transmitted through unsafe sexual practices whereas presently transmission is mainly attributed to sharing of contaminated injection drug equipment among injection drug users (IDUs) [4,5]. As such, IDUs who engage in high-risk HIV behaviours play a critical role in transmitting this viral infection. Specific high-risk HIV activities among IDUs include frequent injections and sharing of syringes or equipment [6]. In Vancouver, independent risk variables of needle sharing included difficulty obtaining sterile needles, requiring help to inject drugs, needle reuse, and frequency of injection [7].

High-risk injecting behaviours have an impact on HIV incidence, but the social context under which IDUs engage in these behaviours is also important [8]. This is evident when needle sharing remains a common practice among IDUs even after needle-exchange programs become available [7]. Demographic characteristics of IDUs such as marital status, socio-economic status, and education have been associated with HIV risk behaviours, as well as HIV-related knowledge $[5,9]$. In addition, the social setting of drug use carries unique risks since injection behaviour can be learned from observing more experienced IDUs [10].

The present study greatly adds to our body of knowledge on this important topic in several meaningful ways. Currently, the underlying causes of the risk indicators that lead the majority of people diagnosed with HIV in Saskatchewan to be IDUs have not been clearly defined. Secondarily, there are no studies in Canada that attempt to initially differentiate and then compare IDU prevalence, behaviours, and characteristics on the basis of higher risk injection drug use (HR IDU) as opposed to lower risk injection drug use (LR IDU). Finally, this study determines both the unadjusted and adjusted risk indicators that lead

*Corresponding author: John Moraros, MD, PhD, MPH, School of Public Health University of Saskatchewan, 107 Wiggins Road Saskatoon, SK S7N 5E5, Canada, Tel: +306-966-8578; E-mail: john.moraros@usask.ca

Received April 16, 2012; Accepted June 04, 2012; Published June 08, 2012

Citation: Moraros J, Falconer J, Rogers M, Lemstra M (2012) Risk Factors Associated with Higher Injection Drug Use and HIV Rates: Findings from Saskatchewan, Canada. J AIDS Clinic Res S1:009. doi:10.4172/2155-6113.S1-009

Copyright: (C 2012 Moraros J, et al. This is an open-access article distributed under the terms of the Creative Commons Attribution License, which permits unrestricted use, distribution, and reproduction in any medium, provided the original author and source are credited. 
Citation: Moraros J, Falconer J, Rogers M, Lemstra M (2012) Risk Factors Associated with Higher Injection Drug Use and HIV Rates: Findings from Saskatchewan, Canada. J AIDS Clinic Res S1:009. doi:10.4172/2155-6113.S1-009

one to become a HR IDU, including demographics, socio-economic status, significant life events, and HIV/AIDS-related knowledge.

\section{Methods}

\section{Study design}

This was a cross sectional study conducted in the SHR, Saskatchewan, and Canada. Ethics approval was obtained from the University of Saskatchewan Behavioral Research Ethics Board (BEH\# 08-53).

\section{Study setting}

The present study was conducted by the Saskatoon Tribal Council and the University of Saskatchewan's School of Public Health. From the months of September 2009 to April 2010, residents at-risk for contracting HIV were recruited from the SHR, Saskatchewan, and Canada to participate in this study.

\section{Participants}

Only adult's ages 18 years old or older, who gave both written and informed consent participated in the study. Eligible residents included current injection drug users, sex trade workers, people who frequently used the services of the sex trade, or men who had sex with other men.
Respondents were given a \$20 honorarium for participating in the survey.

\section{Survey instrument}

The survey used in the present study consisted of 175 questions taken from pre-existing validated questionnaires. It was used to measure demographics, socio-economic status, knowledge, attitudes, and behaviours, barriers to services, depressed mood and significant life events of those at-risk for HIV.

A current injection drug user was defined as someone who answered yes to the question "Have you injected a drug in the last 4 weeks?” IDUs were further divided into HR IDUs and LR IDUs. An IDU was classified as higher risk if he or she answered frequently or sometimes to injecting with needles that have already been used by a sexual partner, friend or acquaintance, or a stranger; using someone else's filter, water, or bleach; drawing up from a used spoon or container; or using a container that someone else keeps used syringes in within the past 30 days. These questions came from the Injecting Risk Questionnaire (IRQ) which has been found to have an overall reliability of .93 and a Cronbach's alpha between .88 and .90 [11].

Demographic and socio-economic status information was collected using questions taken from the Risk Behaviors Assessment

\begin{tabular}{|c|c|c|c|}
\hline & Higher Risk IDUs (\%) & Lower Risk IDUs (\%) & P-value \\
\hline \multicolumn{4}{|l|}{ During the past 4 weeks, how often have you... } \\
\hline Injected with a syringe that was already been used by a sexual partner? & & & .000 \\
\hline Frequently or sometimes & 59.4 & 0.0 & \\
\hline Hardly ever & 12.2 & 18.1 & \\
\hline Never & 28.3 & 81.9 & \\
\hline Injected with a syringe that had already been used by a friend or acquaintance? & & & .000 \\
\hline Frequently or sometimes & 35.1 & 0.0 & \\
\hline Hardly ever & 17.0 & 11.6 & \\
\hline Never & 47.8 & 88.4 & \\
\hline Injected with a syringe that had already been used by a stranger? & & & .000 \\
\hline Frequently or sometimes & 25.2 & 0.0 & \\
\hline Hardly ever & 14.3 & 5.3 & \\
\hline Never & 60.4 & 94.7 & \\
\hline Filled your syringe that had already been used by somebody else? & & & .000 \\
\hline Frequently or sometimes & 33.9 & 0.0 & \\
\hline Hardly ever & 17.8 & 9.5 & \\
\hline Never & 48.3 & 90.5 & \\
\hline Drawn up from a spoon into which someone else had put a used syringe? & & & .000 \\
\hline Frequently or sometimes & 56.1 & 0.0 & \\
\hline Hardly ever & 24.7 & 17.8 & \\
\hline Never & 19.2 & 82.2 & \\
\hline Used a filter which someone else had put a used syringe? & & & .000 \\
\hline Frequently or sometimes & 38.5 & 0.0 & \\
\hline Hardly ever & 19.6 & 9.8 & \\
\hline Never & 41.9 & 90.2 & \\
\hline Used the same water or bleach as someone for flushing or cleaning? & & & .000 \\
\hline Frequently or sometimes & 50.2 & 0.0 & \\
\hline Hardly ever & 15.6 & 15.7 & \\
\hline Never & 34.1 & 84.3 & \\
\hline Used old syringes that were kept in the same container as someone else's old syringes? & & & .000 \\
\hline Frequently or sometimes & 29.9 & 0.0 & \\
\hline Hardly ever & 19.9 & 10.4 & \\
\hline \multirow[t]{2}{*}{ Never } & 50.3 & 89.6 & \\
\hline & $\mathrm{N}=182$ & $\mathrm{~N}=421$ & \\
\hline
\end{tabular}

Table 1: Prevalence of Injection Drug Use Behaviours by IDU Risk Category. 
Citation: Moraros J, Falconer J, Rogers M, Lemstra M (2012) Risk Factors Associated with Higher Injection Drug Use and HIV Rates: Findings from Saskatchewan, Canada. J AIDS Clinic Res S1:009. doi:10.4172/2155-6113.S1-009

Page 3 of 7

Questionnaire created by the National Institute on Drug Abuse. This questionnaire was used in both the Vancouver Injection Drug User Study (VIDUS) and the At Risk Youth Survey (ARYS) projects [4,1214]. The reliability of the survey in regards to IDUs reporting their own socio-economic status was deemed to be acceptable (kappa coefficients $=.78$ to 1.00$)$ [15].

Participant's HIV/AIDS-related knowledge was measured using a series of 28 true and false questions. These questions were taken from the Health and Relationships Survey, AIDS Preventive Behaviors, which has been found to have a reliability alpha ranging from .68 to $.72[16]$.

Behaviors associated with increased risk of HIV infection, such as trading sex, number of sex partners, frequency of injection, and sharing of injecting equipment were measured using the Risk Behaviors Assessment (RBA) Questionnaire. The RBA Questionnaire asks whether a participant has ever traded sex for drugs, traded sex for money, or traded drugs for sex. The Spearman correlations for these questions are $\mathrm{r}=.66, \mathrm{r}=.72$ and $\mathrm{r}=.78$ respectively [17].

\section{Statistical analysis}

Cross tabulations were performed with chi square tests initially between demographics, socioeconomic status, significant life events, HIV/AIDS-related knowledge, and other HIV risk behaviours by risk category among IDUs. After these initial cross tabulations, hierarchal well formulated binary logistic regression was used to determine the

\begin{tabular}{|c|c|c|c|c|}
\hline & Non- IDUs (\%) & Higher Risk IDUs (\%) & Lower Risk IDUs (\%) & ${ }^{*} \mathrm{P}$-value \\
\hline Gender & & & & .541 \\
\hline Male & 63.2 & 56.4 & 53.6 & \\
\hline Female & 36.8 & 43.6 & 46.4 & \\
\hline Age category & & & & .866 \\
\hline $18-29$ & 28.7 & 26.5 & & \\
\hline $30-39$ & 27.6 & 35.9 & 34.7 & \\
\hline $40-69$ & 43.7 & 37.6 & 36.5 & \\
\hline Sexual orientation & & & & .039 \\
\hline Straight & 89.6 & 85.2 & 91.1 & \\
\hline Bisexual, gay or lesbian, two-spirited, other & 10.4 & 14.8 & 8.9 & \\
\hline Marital status & & & & .325 \\
\hline Single (never married) & 59.1 & 57.2 & 51.2 & \\
\hline Married or common law & 23.6 & 30.6 & 32.5 & \\
\hline Separated/divorced, widowed or other & 17.3 & 12.2 & 16.3 & \\
\hline Cultural status & & & & .919 \\
\hline Caucasian or other & 17.0 & 11.5 & 11.2 & \\
\hline Aboriginal (First Nations, Métis or Inuit) & 83.0 & 88.5 & 88.2 & \\
\hline Highest level of school completed & & & & .528 \\
\hline Grade 8 or less & 12.1 & 21.4 & 17.5 & \\
\hline $\begin{array}{l}\text { Grade } 9-12 \text { but no high school } \\
\text { graduation }\end{array}$ & 62.3 & 53.8 & 55.6 & \\
\hline Completed secondary or post-secondary & 25.6 & 24.7 & 26.9 & \\
\hline Living arrangements & & & & .814 \\
\hline Own home or apartment & 42.4 & 38.3 & 41.1 & \\
\hline Someone else's home or apartment & 41.8 & 45.0 & 45.3 & \\
\hline Somewhere else & 15.8 & 16.7 & 15.4 & \\
\hline Homeless & & & & .004 \\
\hline Yes & 15.8 & 44.0 & 31.2 & \\
\hline No & 72.3 & 56.0 & 68.8 & \\
\hline Employment & & & & .871 \\
\hline Unemployed & 50.6 & 54.1 & 53.7 & \\
\hline Working part-time or full-time & 11.0 & 7.2 & 9.3 & \\
\hline Disabled, not able to work & 21.2 & 25.4 & 24.8 & \\
\hline Something else & 17.2 & 13.3 & 12.2 & \\
\hline \multicolumn{5}{|l|}{ Sources of income } \\
\hline Paid job, salary or business & 16.2 & 9.3 & 9.8 & .876 \\
\hline Social security, disability, Workmen's comp & 41.3 & 45.6 & 41.1 & .325 \\
\hline Sell or trade goods, barter & 4.2 & 6.6 & 9.2 & .309 \\
\hline Illegal or possibly illegal activity & 4.7 & 15.0 & 11.5 & .280 \\
\hline Prostitution & 1.7 & 14.3 & 7.4 & .012 \\
\hline Other & 24.7 & 24.7 & 29.9 & .212 \\
\hline \multicolumn{5}{|l|}{ Annual household income } \\
\hline$\$ 0-\$ 9,999$ & 71.8 & 75.6 & 68.2 & .093 \\
\hline \multirow[t]{2}{*}{ Average annual household income } & $\$ 7,812$ & $\$ 8,415$ & $\$ 10,017$ & \\
\hline & $N=397$ & $\mathrm{~N}=182$ & $N=421$ & \\
\hline
\end{tabular}

Table 2: Demographics and Socio-economic Status of Non-IDUs, Higher Risk IDUs and Lower Risk IDUs. 
Citation: Moraros J, Falconer J, Rogers M, Lemstra M (2012) Risk Factors Associated with Higher Injection Drug Use and HIV Rates: Findings from Saskatchewan, Canada. J AIDS Clinic Res S1:009. doi:10.4172/2155-6113.S1-009

Page 4 of 7

\begin{tabular}{|c|c|c|c|c|}
\hline & Non- IDUs (\%) & Higher Risk IDUs (\%) & Lower Risk IDUs (\%) & *P-value \\
\hline \multicolumn{5}{|l|}{ Experienced: } \\
\hline Physical assault or abuse in their adult life by their partner & 53.9 & 65.9 & 59.3 & .144 \\
\hline Physical assault or abuse in their adult life by someone other than their partner & 55.4 & 68.4 & 56.9 & .011 \\
\hline Physical assault or abuse as a child & 60.1 & 70.5 & 65.0 & .218 \\
\hline Seeing people hitting or harming one another in their family while growing up & 76.6 & 86.3 & 81.9 & .210 \\
\hline Sexual assault in their adult life & 33.0 & 44.1 & 35.8 & .068 \\
\hline Sexual assault as a child & 47.7 & 59.7 & 49.8 & .035 \\
\hline Seeing someone physically assaulted or abused & 74.6 & 82.0 & 81.4 & .870 \\
\hline $\begin{array}{l}\text { Seeing someone seriously } \\
\text { injured or violently killed }\end{array}$ & 53.2 & 56.9 & 59.6 & .552 \\
\hline Losing a child through death & 27.0 & 33.3 & 27.7 & .187 \\
\hline $\begin{array}{l}\text { Death or permanent separation from a parent or someone who was like a parent before } 18 \text { years } \\
\text { of age }\end{array}$ & 44.8 & 52.6 & 50.9 & .718 \\
\hline $\begin{array}{l}\text { Death of a spouse, partner, or } \\
\text { loved one as an adult }\end{array}$ & 47.7 & 52.1 & 57.2 & .274 \\
\hline Attended a Residential School & 27.0 & 32.9 & 34.4 & .738 \\
\hline \multirow[t]{2}{*}{ Had a parent or grandparent who attended Residential School } & 62.4 & 63.2 & 66.6 & .452 \\
\hline & $\mathrm{N}=397$ & $\mathrm{~N}=182$ & $\mathrm{~N}=421$ & \\
\hline
\end{tabular}

${ }^{*} \mathrm{P}$-value has been calculated by comparing the Higher-Risk and Lower-Risk IDUs groups

Table 3: Comparison of Significant Life Events of Non-IDUs, Higher Risk IDUs and Lower Risk IDUs

association between the outcome variable of being higher risk IDU (in comparison to being a lower risk IDU) and all potential explanatory variables. The unadjusted effect of each covariate was determined and then entered one step at a time based on changes in the $-2 \log$ likelihood and the Wald Test [18]. The final results are presented as adjusted odds ratios with 95 percent confidence intervals.

\section{Results}

There were 1,000 at-risk individuals who participated in this study, 603 of whom identified them as an IDU. This sample represented $76.6 \%$ of the known IDUs currently residing in Saskatoon, as identified by service information provided by the SHR [18]. Of these 603 participants, 182 (30.2\%) were categorized as HR IDUs. Of the $182 \mathrm{HR}$ IDUs, examples of high risk behaviours included $59.4 \%$ frequently or sometimes injecting with a syringe that was already used by a sexual partner, 56.1\% frequently or sometimes drawing up from a spoon into which someone else had put a used syringe, and $50.2 \%$ frequently or sometimes using the same water or bleach as someone else for flushing or cleaning their syringe (Table 1 ).

The majority of the study participants, irrespective of intravenous drug use (i.e. non-IDUs) and risk group category classification (i.e. HR vs. LR IDUs) were male, between the ages of 40-69 years old, heterosexual, single, and self-identified as being Aboriginal. Additionally, they had less than a grade 12 education; did not own their own home or apartment; were unemployed, had a source of income from social assistance, and had an annual household income of less than $\$ 10,000$ (Table 2).

By specifically comparing the two risk groups (i.e. HR vs. LR IDUs) it was determined that prostitution as a source of income was more prevalent within the group of HR IDUs than LR IDUs (14.3\% and 7.4\% respectively). Moreover, $75.6 \%$ of HR IDUs had an annual household income between $\$ 0-\$ 9,999$ compared to $68.2 \%$ of LR IDUs, although this difference was not statistically significant. However, significant differences did exist on the basis of sexual orientation and homelessness with more HR IDUs being bisexual, gay, or lesbian and homeless when compared to LR IDUs ( $14.8 \%$ vs. $8.9 \%$ and $44.0 \%$ vs. $31.2 \%$ respectively) (Table 2).

The majority of the study participants, irrespective of intravenous drug use (i.e. non-IDUs) and risk group category classification (i.e. HR vs. LR IDUs) experienced multiple significant life events such as physical assault or abuse in their adult life; physical assault or abuse as a child; seeing people hitting or harming one another in their family while growing up; seeing someone physically assaulted or abused; and having a parent or grandparent who attended Residential School (Table $3)$.

In particular, HR IDUs were significantly more likely than LR IDUs to have been physically assaulted or abused in their adult life by someone other than their partner (68.4\% compared to 56.9\%) and more likely to have been sexually assaulted both as a child (59.7\% compared to $49.8 \%$ ) and as an adult (44.1\% compared to $35.8 \%$ ) (Table 3 ).

Insofar as HIV/AIDS knowledge was concerned, HR IDUs were significantly more likely to incorrectly answer as true the following two HIV-related knowledge statements "pregnant women are safe from getting HIV infection" and "pulling out the penis before a man climaxes keeps a woman from getting HIV during sex" when compared to LR IDUs. Furthermore, the risk behavioral variables that differed significantly between HR and LR IDUs included giving sex to get drugs and giving someone drugs to have sex (Table 4).

After multivariate regression analysis, the three statistically significant independent risk indicators for being a HR IDU, in comparison to a LR IDU, included experiencing sexual assault as a child, being homeless, and incorrectly answering the statement, "pulling out the penis before a man climaxes keeps a woman from getting HIV during sex" (Table 5).

\section{Discussion}

It is critical that HIV prevention interventions are targeted to the highest-risk IDUs, such as those who are at highest risk of HIV infection and overdose [19]. Despite this importance, very few research articles have attempted to separate higher and lower risk IDU. The present study adds to the literature by: a) outlining the underlying causes of the risk indicators of being infected with HIV, b) initially separating and then comparing the characteristics and practices of higher and lower risk IDUs, and c) determining the covariates that are independently associated with the risk indicators of HR IDU. 
Citation: Moraros J, Falconer J, Rogers M, Lemstra M (2012) Risk Factors Associated with Higher Injection Drug Use and HIV Rates: Findings from Saskatchewan, Canada. J AIDS Clinic Res S1:009. doi:10.4172/2155-6113.S1-009

Page 5 of 7

\begin{tabular}{|c|c|c|c|}
\hline & Higher Risk IDUs (\%) & Lower Risk IDUs (\%) & P-value \\
\hline \multicolumn{4}{|l|}{ Knowledge Variables: } \\
\hline Pregnant women are safe from getting HIV infection & & & .041 \\
\hline True & 9.3 & 4.7 & \\
\hline False & 90.7 & 95.3 & \\
\hline Pulling out the penis before a man climaxes keeps a woman from getting HIV during sex & & & .049 \\
\hline True & 13.4 & 8.0 & \\
\hline False & 86.6 & 92.0 & \\
\hline \multicolumn{4}{|l|}{ Other Risk Variables: } \\
\hline Ever given sex to get money & & & 349 \\
\hline Yes & 39.8 & 35.6 & \\
\hline Ever given sex to get drugs & & & .002 \\
\hline Yes & 42.9 & 29.3 & \\
\hline Ever given someone drugs to have sex with you? & & & .026 \\
\hline Yes & 20.9 & 13.4 & \\
\hline How many people have you had oral, anal or vaginal sex with in the past 30 days? & & & .096 \\
\hline 0 people & 24.3 & 31.8 & \\
\hline 1 or 2 people & 54.3 & 52.9 & \\
\hline 3 or more people & 21.4 & 15.3 & \\
\hline Frequency of injection in past 30 days & & & .621 \\
\hline$<60$ times & 74.7 & 76.7 & \\
\hline \multirow[t]{2}{*}{$61+$} & 25.3 & 23.3 & \\
\hline & $\mathrm{N}=182$ & $\mathrm{~N}=421$ & \\
\hline
\end{tabular}

Table 4: HIVIAIDS-related Knowledge and Risk Behaviour Differences between Higher Risk IDUs and Lower Risk IDUs.

\begin{tabular}{|c|c|c|c|}
\hline & OR & 95\% Confidence Interval & P-value \\
\hline \multicolumn{4}{|l|}{ Independent variables: } \\
\hline Consider self to be homeless...Yes & 1.75 & $1.19-2.59$ & .005 \\
\hline $\begin{array}{l}\text { Pulling out the penis before a man climaxes keeps a woman from getting HIV during sex... } \\
\text { True }\end{array}$ & 1.94 & $1.05-3.60$ & .035 \\
\hline Sexual assault as a child...Yes & 1.48 & $1.01-2.18$ & .047 \\
\hline
\end{tabular}

Reference categories:

Does not consider self to be homeless

Pulling out the penis before a man climaxes keeps a woman from getting HIV during sex...False

No sexual assault as a child

Hosmer-Lemeshow test $=.995$

Nagelkerke R Squared $=.047$

Table 5: Independent Risk Indicators of being a Higher Risk IDU in SHR.

The risk indicators of being infected with HIV among IDUs have been previously studied. It has been reported that HIV is associated with injection drug use frequency, the practice of injecting with used needles, the frequency of injecting cocaine, and sharing needles with others $[8,20]$. In this study, the researchers observed an epidemiological shift in the underlying causes of the risk indicators among HIV infected individuals in the SHR, Canada from men having sex with men to heterosexuals, predominately whites to predominately Aboriginals, middle/high SES to low SES, and mainly a sexual mode of transmission to mainly an IDU mode of transmission.

The practice of IDU is rapidly increasing in the SHR, Saskatchewan, Canada, among all sociodemographic sectors and especially among its Aboriginal population [5]. This in large part helps explain the concomitant increases in HIV prevalence rates observed in the region during the last decade.

In the present study, the main characteristics of HR IDUs were highly reflective of their injecting behaviours and practices. Our findings indicate that HR IDUs were more likely to be drug-dependent, inject with others, and share injecting equipment when compared to LR IDUs. These findings are widely supported in the literature. A study conducted in the US found higher rates of injection risk behaviour among IDUs who reported injecting with others and sharing injection equipment [21]. Our findings help highlight the importance of making clean needles and syringes easily accessible to IDU in the SHR if we are to successfully combat the rapid rise in HIV rates.

Lastly, the present study determined which covariates are independently associated with HR injecting practices in the SHR, Saskatchewan, and Canada. The first independent risk factor for being a HR IDU was having experienced sexual assault as a child. Previous studies have also found an independent association between injection drug use and childhood sexual abuse, particularly age of initiation [22]. Our finding adds that sexual abuse as a child is not only a risk factor for earlier injection drug use, but also a risk factor for HR injecting. Since childhood sexual assault has been noted to account for one half to two thirds of serious problems with drug use, mental health interventions such as screening and treatment of sexual assault survivors may be necessary to prevent the victims from becoming IDUs who might test positive for HIV in the future [22].

Being homeless was also a risk indicator for HR IDU. This is consistent with previous studies that have found associations between HIV risk behaviours among IDUs and unstable housing [23]. It has been demonstrated that IDUs who have unstable housing are 
Citation: Moraros J, Falconer J, Rogers M, Lemstra M (2012) Risk Factors Associated with Higher Injection Drug Use and HIV Rates: Findings from Saskatchewan, Canada. J AIDS Clinic Res S1:009. doi:10.4172/2155-6113.S1-009

independently associated with multiple HIV risk behaviours such as injecting with used needles and trading sex [23]. Developing a strong housing strategy that increases affordable housing programs could help stabilize the living environment of IDUs and increase access to better self-care.

Finally, we found that lack of knowledge about HIV transmission through sexual practices was also an indicator for HR injecting. This finding contrasts with other studies that have found that HIV knowledge levels do not have a significant association with engaging in HIV risk behaviour among IDUs $[9,24]$.

These three independent covariates address the larger social context of injection drug use within the SHR, Saskatchewan, Canada. Substance abuse prevention alone is not sufficient, but post sexual assault and victimization services and housing stability must be part of a multifaceted approach in order to improve the social-environmental context [22]. Public health education is also pertinent for HIV prevention and safe sex practices.

\section{Limitations}

There were a few limitations associated with this particular study. It was cross-sectional in nature, and therefore, unable to determine causation. Additionally, the results were based on self-reported information, although the questionnaires used were all valid and reliable.

\section{Recommendations}

The increase of HIV positive test reports in Saskatchewan, Canada, and the fact that the majority of new HIV cases are attributed to injection drug use, are concerning. These should be key areas of public health intervention. This study suggests that HR injecting is independently associated with three covariates: sexual assault as a child, homelessness, and lack of knowledge regarding HIV transmission. These independent variables represent vital areas for policy and program development for this vulnerable and hard to reach population.

The diverse and complex issues associated with HIV transmission and IDU in Saskatchewan, Canada continue to evolve $[25,26]$. The following recommendations may be of benefit in dealing with the unique dynamics of HIV and IDU in the study group: 1) Sexual assault victims be offered an opportunity to participate in peer outreach programs specifically designed to address the dangers of HIV transmission and IDU; 2) Support be provided for homeless individuals through grassroots initiatives and creative interventions to address their needs. These may include emergency housing provisions, drop-in centers, and safe houses; 3) Former drug users be involved in the HIV and IDU education of current injection drug users, individuals living high-risk lifestyles, and public health professionals; 4) That the unique issues regarding the spread of HIV transmission and IDU faced by Aboriginal peoples and especially its youth, be identified and addressed through non-judgmental, culturally appropriate, and Aboriginal led interventions; and 5) Further research be conducted in Saskatchewan on the sociocultural and economic factors (i.e. norms, attitudes, beliefs, biases) that influence high risk behaviors, injection practices, and lifestyles choices in the injection drug-using subculture in order to better inform public health professionals in the development of interventions in the areas of prevention, treatment, and evaluation.

\section{Acknowledgments}

Public Health Agency of Canada, West Side Community Clinic, Saskatoon Health Region, AIDS Saskatoon, and the Friendship Inn.

\section{References}

1. Public Health Agency of Canada. HIV and AIDS in Canada: Surveillance report December 31, 2008. Surveillance and Risk Assessment Division, Centre for Communicable Disease and Infection Control, Public Health Agency of Canada, 2009.

2. Saskatchewan Ministry of Health (2009) HIV and AIDS in Saskatchewan 2008 Population Health Branch, Saskatchewan Ministry of Health.

3. Saskatchewan Ministry of Health (2009) HIV and AIDS in Canada 2008 Population Health Branch, Saskatchewan Ministry of Health.

4. Wood E, Montaner JS, Li K, Zhang R, Barney L, et al. (2008) Burden of HIV infection among Aboriginal injection drug users in Vancouver, British Columbia. Am J Public Health 98: 515-519.

5. Lemstra M, Rogers M, Thompson A, Moraros J, Buckingham R (2012) Risk Indicators Associated with Injection Drug Use Among the Aboriginal Population. AIDS Care.

6. Deren S, Beardsley M, Coyle S, Singer M, Kang SY (2000) HIV risk behaviors among injection drug users in low, medium, and high seroprevalence communities. AIDS Behav 5: 45-50.

7. Wood E, Tyndall MW, Spittal PM, Li K, Kerr T, et al. (2001) Unsafe injection practices in a cohort of injection drug users in Vancouver: Could safer injecting rooms help? Can Med Assoc J 165: 405-410.

8. Schoenbaum EE, Hartel D, Selwyn PA, Klein RS, Davenny K, et al. (1989) Risk factors for human immunodeficiency virus infection in intravenous drug users. N Engl J Med 321: 874-879.

9. Maqsood N, Malik JA, Bhatti MR, Ahmad I, Luqman S, et al. (2009) HIVIAIDS risk behaviours among injecting drug users: Addressing development of risk behaviour knowledge and patterns of risk behaviour practices in context of demographic characteristics. Ann Intern Med 15: 93-100.

10. Latkin CA, Knowlton AR, Hoover D, Mandell W (1999) Drug network characteristics as a predictor of cessation of drug use among adult injection drug users: a prospective study. Am J Drug Alcohol Abuse 25: 463-473.

11. Stimson G, Jones S, Chalmers C, Sullivan D (1998) A short questionnaire (IRQ) to assess injecting risk behaviour. Addiction 93: 337-347.

12. Craib KJP, Spittal PM, Wood E, Laliberte N, Hogg RS, et al. (2003) Risk factors for elevated HIV incidence among Aboriginal injection drug users in Vancouver. Can Med Assoc J 168: 19-24.

13. Kerr T, Stoltz J, Marshall B, Lai C, Strathdee SA, et al. (2009) Childhood trauma and injection drug use among high risk youth. J Adolesc Health 45: 300-302.

14. British Columbia Center for Excellence in HIVIAIDS (2006) Combined (ARYS/ ACCESS/VIDUS 2) follow-up questionnaire. Vancouver, BC: Providence Health Care, St. Paul's Hospital, The University of British Columbia, and Vancouver Coastal Health.

15. Johnson ME, Fisher DG, Reynolds GL (1999) Reliability of drug users' selfreport of economic variables. Addict Res 7: 227-238.

16. Terri DF, Clive MD, William LY, Sandra LD (2010) Handbook of SexualityRelated Measures (3rdedn), Routledge, US.

17. Johnson ME, Fisher DG, Montoya I, Booth R, Rhodes F, et al. (2000) Reliability and validity of not-in-treatment drug users' follow-up self-report.

18. Rothman KJ, Greenland S (1998) Modern Epidemiology, (2ndedn), Philadelphia: Lippincott Williams and Wilkins.

19. Wood E, Tyndall MW, Li K, Lloyd-Smith E, Small W, et al. (2005) Do supervised injecting facilities attract higher-risk injection drug users? Am J Prev Med 29: 126-130.

20. Hagan H, Campbell JV, Thiede H, Strathdee SA, Ouellet L, et al. (2007) Injecting alone among young adult IDUs in five US cities: evidence of low rates of injection risk behavior. Drug Alcohol Depend 91: S48-S55.

21. Ompad DC, Ikeda RM, Shah N, Fuller CM, Bailey S, et al. (2005) Childhood sexual abuse and age at initiation of injection drug use. Am J Public Health 95: 703-709.

22. Dube SR, Felitti VJ, Dong M, Chapman DP, Giles WH (2003) Childhood abuse neglect, and household dysfunction and the risk of illicit drug use: The adverse childhood experiences study. Pediatrics 111: 564-572.

23. Corneil TA, Kuyper LM, Shoveller J, Hogg RS, Li K, et al. (2006) Unstable 
Citation: Moraros J, Falconer J, Rogers M, Lemstra M (2012) Risk Factors Associated with Higher Injection Drug Use and HIV Rates: Findings from Saskatchewan, Canada. J AIDS Clinic Res S1:009. doi:10.4172/2155-6113.S1-009

housing, associated risk behaviour, and increased risk for HIV infection among injection drug users. Health Place 12: 79-85.

24. Holtzman D, Lowry R, Kann L, Collins JL, Kolbe LJ (1994) Changes in HIV related information sources, Instruction Knowledge and Behaviour among US high school students, 1989 and 1990. Am J Public Health 84: 388-393.
25. At Risk: Recommendations for a Strategy on HIV, Blood-borne Pathogens and Injection Drug Use. Saskatchewan Ministry of Health, Population Health Branch, 2002

26. Saskatchewan's HIV Strategy 2010-2014. Saskatchewan Ministry of Health, Population Health Branch, 2010. 